\title{
Complete genome sequence of the extremely halophilic Halanaerobium praevalens type strain $\left(\mathrm{GSL}^{\mathrm{T}}\right)$
}

\author{
Natalia Ivanova ${ }^{1}$, Johannes Sikorski ${ }^{2}$, Olga Chertkov ${ }^{1,3}$, Matt Nolan ${ }^{1}$, Susan Lucas ${ }^{1}$, Nancy \\ Hammon $^{1}$, Shweta Deshpande ${ }^{1}$, Jan-Fang Cheng ${ }^{1}$, Roxanne Tapia ${ }^{1,3}$, Cliff Han ${ }^{1,3}$, Lynne \\ Goodwin ${ }^{1,3}$, Sam Pitluck' ${ }^{1}$, Marcel Huntemann', Konstantinos Liolios ${ }^{1}$, Ioanna Pagani ${ }^{1}$, \\ Konstantinos Mavromatis ${ }^{1}$, Galina Ovchinikova ${ }^{1}$, Amrita Pati ${ }^{1}$, Amy Chen ${ }^{4}$, Krishna \\ Palaniappan ${ }^{4}$, Miriam Land ${ }^{1,5}$, Loren Hauser ${ }^{1,5}$, Evelyne-Marie Brambilla2, K. Palani Kannan², \\ Manfred Rohde ${ }^{6}$, Brian J. Tindall ${ }^{2}$, Markus Göker ${ }^{2}$, John C. Detter ${ }^{1,3}$, Tanja Woyke ${ }^{1}$, James \\ Bristow $^{1}$, Jonathan A. Eisen ${ }^{1,7}$, Victor Markowitz ${ }^{4}$, Philip Hugenholtz ${ }^{1,8}$, Nikos C. Kyrpides ${ }^{1}$, \\ Hans-Peter Klenk ${ }^{2}$, and Alla Lapidus ${ }^{{ }^{*}}$ \\ ${ }^{1}$ DOE Joint Genome Institute, Walnut Creek, California, USA \\ ${ }^{2}$ DSMZ - German Collection of Microorganisms and Cell Cultures GmbH, Braunschweig, \\ Germany \\ ${ }^{3}$ Los Alamos National Laboratory, Bioscience Division, Los Alamos, New Mexico, USA \\ ${ }^{4}$ Biological Data Management and Technology Center, Lawrence Berkeley National \\ Laboratory, Berkeley, California, USA \\ ${ }^{5}$ Oak Ridge National Laboratory, Oak Ridge, Tennessee, USA \\ ${ }^{6} \mathrm{HZI}$ - Helmholtz Centre for Infection Research, Braunschweig, Germany \\ ${ }^{7}$ University of California Davis Genome Center, Davis, California, USA \\ ${ }^{8}$ Australian Centre for Ecogenomics, School of Chemistry and Molecular Biosciences, The \\ University of Queensland, Brisbane, Australia
}

*Corresponding author: Alla Lapidus

Keywords: strictly anaerobic, non-motile, Gram-negative, straight rod-shaped, halophilic, moderate alkaliphile, mesophilic, chemoorganotroph, Halanaerobiaceae, GEBA

Halanaerobium praevalens Zeikus et al. 1984 is the type species of the genus Halanaerobium, which in turn is the type genus of the family Halanaerobiaceae. The species is of interest because it is able to reduce a variety of nitro-substituted aromatic compounds at a high rate, and because of its ability to degrade organic pollutants. The strain is also of interest because it functions as a hydrolytic bacterium, fermenting complex organic matter and producing intermediary metabolites for other trophic groups such as sulfate-reducing and methanogenic bacteria. It is further reported as being involved in carbon removal in the Great Salt Lake, its source of isolation. This is the first completed genome sequence of a representative of the genus Halanaerobium and the second genome sequence from a type strain of the family Halanaerobiaceae. The 2,309,262 bp long genome with its 2,110 protein-coding and 70 RNA genes is a part of the Genomic Encyclopedia of Bacteria and Archaea project.

\section{Introduction}

Strain GSLT (= DSM $2228=$ ATCC 33744) is the type strain of the species Halanaerobium praevalens, which is the type species of its genus Halanaerobium [1]. Originally described as Haloanaerobium [2], the name was later changed to Halanaerobium to conform with rule 61 of the Bacteriological Code [3]. The genus currently consists of nine validly named species [4]. The genus name is derived from the Latinized Greek word hals; halos meaning salt, the Latinized Greek word an- meaning not, the Latinized Greek word aer meaning air and the Lati- nized Greek word bios meaning life, yielding the Neo-Latin word 'Halanaerobium' meaning 'salt organism which grows in the absence of air' [4]. The species epithet is derived from the Latin word 'praevalens' (very powerful, very strong, here prevalent) [4]. Strain GSL ${ }^{T}$ was isolated from the hypersaline surface sediments of Great Salt Lake, Utah, USA [2]. Further strains of $H$. praevalens have been isolated from canned salted Swedish fermented herrings referred to as Surströmming [5] and probably also from the Red Sea [6]. Other 
members of the genus have been isolated also from high salt environments distributed worldwide [710]. The enzymatic activities of the fatty acid synthetase complex and the D-BAPA (N'-benzoylarginine- $p$-nitroanilide)-ase of $H$. praevalens have been studied in more detail [11,12]. Here we present a summary classification and a set of features for $H$. praevalens strain GSLT, together with the description of the complete genome sequencing and annotation.

\section{Classification and features}

A representative genomic 16S rRNA sequence of $H$. praevalens was compared using NCBI BLAST under default values (e.g., considering only the best 250 hits) with the most recent release of the Greengenes database [13] and the relative frequencies, weighted by BLAST scores, of taxa and keywords (reduced to their stem [14]) were determined. The five most frequent genera were Halanaerobium (81.9\%), Halothermothrix (7.8\%), Halanaerobacter $(2.7 \%)$, Acetohalobium (2.3\%) and Natroniella (1.9\%). Regarding hits to sequences from other members of the genus, the average identity within HSPs (high-scoring segment pairs) was $97.8 \%$, whereas the average coverage by HSPs was $96.3 \%$. The species yielding the highest score was Halanaerobium saccharolyticum. (Note that the Greengenes database uses the INSDC (= EMBL/NCBI/DDBJ) annotation, which is not an authoritative source for nomenclature or classification.) The five most frequent keywords within the labels of environmental samples which yielded hits were 'microbi' (9.4\%), 'hypersalin' (9.1\%), 'mat' (8.6\%), 'len, miniprim, new, view, world' (8.5\%) and 'food' (3.4\%). The single most frequent keyword within the labels of environmental samples which yielded hits of a higher score than the highest scoring species was 'hypersalin, len, mat, microbi, miniprim, new, view, world' (12.5\%). These key words are in line with the ecology and the niche from where strains of $H$. praevalens have been isolated.

Figure 1 shows the phylogenetic neighborhood of H. praevalens $\mathrm{GSL}^{\mathrm{T}}$ in a $16 \mathrm{~S}$ rRNA gene based tree. The sequences of the four $16 \mathrm{~S}$ rRNA gene copies in the genome differ from each other by up to five nucleotides, and differ by up to five nucleotides from the previously published $16 \mathrm{~S}$ rRNA gene sequence (AB022034).

The cells of strain GSL ${ }^{\mathrm{T}}$ are straight and rod-shaped $(1 \times 2.4 \mu \mathrm{m})$ (Figure 2) when grown to the mid-log phase at $37^{\circ} \mathrm{C}$ on $\mathrm{CS}$ medium containing $12.5 \%$ $\mathrm{NaCl}$ and $0.5 \%$ glucose [2]. When grown at higher
$\mathrm{NaCl}$ concentrations ( $>20 \%$ ) the cells appear granulated and shorter in length [2]. Single colonies were reported as white to translucent in color, 0.5$2.0 \mathrm{~mm}$ in diameter, and glistened, when grown on agar plates containing CS medium, $12.5 \% \mathrm{NaCl}$, and $0.5 \%$ glucose [2]. $H$. praevalens cells stain Gramnegative [2] and electron microscopy in thin section revealed architectural features typical of Gram-negative bacteria [2]. However, the positive $D$-BAPA-ase reaction [11] confirms its phylogenetic affiliation to the endospore-forming firmicutes (Table 1 ). In this respect, $H$. praevalens is able to hydrolyze only the D- but not the L- isomer of $\mathrm{N}^{\prime}$ benzoyl-arginine- $p$-nitroanilide (BAPA) [11]. The activity of $D$-BAPA-ase was highest at low $\mathrm{NaCl}$ concentration $(100 \mathrm{mM})$ and completely inhibited at $\mathrm{NaCl}$ concentration equal or higher than $1.0 \mathrm{M}$ $(\sim 12 \%)$ [11]. Strain GSLT is described to be nonmotile, although many flagellar genes have been identified in the genome (see below). Other isolates of $H$. praevalens were described as motile $[5,6]$, as were other members of the genus $[7,9,10]$, suggesting strain GSL ${ }^{\mathrm{T}}$ is atypical with regard to motility. The organism is a strictly anaerobic chemoorganotroph [2]. It grows at $\mathrm{NaCl}$ concentrations between $2 \%$ and $30 \%$, with optimal growth at approximately $13 \%$ [2]. The doubling time is $4 \mathrm{~h}$ at $12.5 \% \mathrm{NaCl}$ and $7 \mathrm{~h}$ at $25 \% \mathrm{NaCl}$ in complex CS medium [2]. The temperature range for growth ranges from $5^{\circ} \mathrm{C}$ to $60^{\circ} \mathrm{C}$, with an optimum at $37^{\circ} \mathrm{C}$ [2]. The $\mathrm{pH}$ range for growth is between 6.0 and 9.0, with an optimum at pH between 7.0 and 7.4 [2]. Strain GSLT is able to utilize carbohydrates (including pectin and $\mathrm{N}$-acetylglucosamine), amino acids, yeast extract, and trypticase; the two latter serving as carbon and energy sources on complex medium [2]. The fermentation of glucose yielded butyrate, acetate, propionate, $\mathrm{H}_{2}$, and $\mathrm{CO}_{2}$ as major products [2]. Also, fructose, D-mannose and maltose are utilized and methionine is transformed to methylmercaptan [2]. Penicillin, tetracycline, cycloserine, chloramphenicol (each at $100 \mu \mathrm{g} / \mathrm{ml}$ culture) or sodium azide $(500 \mu \mathrm{g} / \mathrm{ml})$ completely inhibit the growth of $H$. praevalens [2]. Strain GSL ${ }^{\mathrm{T}}$ was also able to degrade nitro-substituted aromatic compounds such as nitrobenzene, $o$-nitrophenol, $m$-nitrophenol, $p$ nitrophenol, 2,4-dinitrophenol, and 2,4-dinitroaniline [34]. The fatty acid synthetase of $H$. praevalens is only slightly inhibited at $17.5 \%$ and was the first reported to be active in the presence of high salt concentrations [12]. H. praevalens was reported to be involved in carbon sequestration in the Great Salt Lake [35], since it is present in the sediments of 
this lake in high numbers $\left(\geq 10^{8}\right.$ cells $\left./ \mathrm{ml}\right)[2,36]$. $H$. praevalens regulates its internal osmotic pressure by the accumulation of salts $\left(\mathrm{Na}^{+}, \mathrm{K}^{+}, \mathrm{Cl}\right)$ rather than by compatible solutes [36]. High concentrations of these salts were measured inside the cells, in sufficient concentration to be isotonic or hypertonic with the medium [37]. Thiosulfate reduction and rhodanese-like enzyme (thiosulfate:cyanide sulfur-transferase) activities also tested positive in strain GSLT [8]. Early in 1987, Matheson et al. [38] established the primary structure of the ribosomal A-protein of the strain GSL ${ }^{\mathrm{T}}$, which is the equivalent to the ribosomal protein L12 from Escherichia coli.

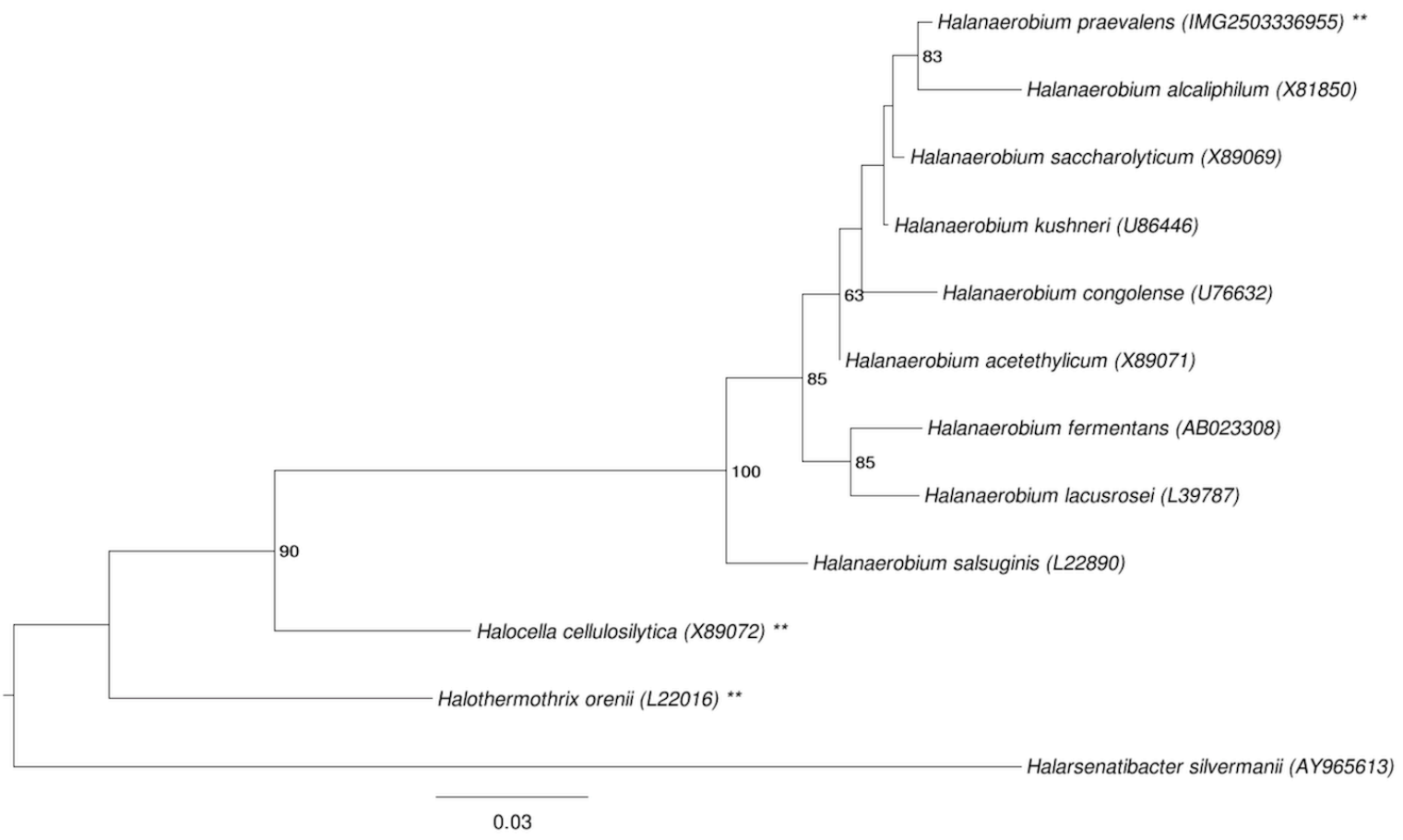

Figure 1. Phylogenetic tree highlighting the position of $H$. praevalens $\mathrm{GSL}^{\top}$ relative to the other type strains within the family Halanaerobiaceae. The tree was inferred from 1,460 aligned characters $[15,16]$ of the 16S rRNA gene sequence under the maximum likelihood criterion [17] and rooted in accordance with the current taxonomy. The branches are scaled in terms of the expected number of substitutions per site. Numbers to the right of bifurcations are support values from 1,000 bootstrap replicates [18] if larger than $60 \%$. Lineages with type strain genome sequencing projects registered in GOLD [19] are labeled with an asterisk, published genomes with two asterisks [20].

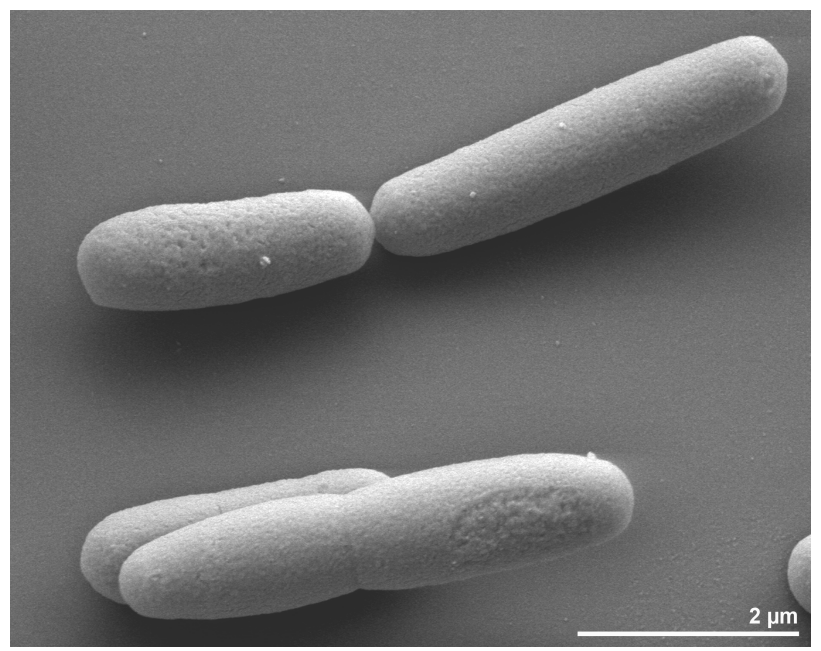

Figure 2. Scanning electron micrograph of $H$. praevalens $\mathrm{GSL}^{\mathrm{T}}$ 
Table 1. Classification and general features of $H$. praevalens $\mathrm{GSL}^{\top}$ according to the MIGS recommendations [21] and the NamesforLife database [22].

\begin{tabular}{|c|c|c|c|}
\hline MIGS ID & Property & Term & Evidence code \\
\hline & \multirow{8}{*}{ Current classification } & Domain Bacteria & TAS [23] \\
\hline & & Phylum Firmicutes & TAS $[24,25]$ \\
\hline & & Class Clostridia & TAS $[26,27]$ \\
\hline & & Order Halanaerobiales & TAS [28-30] \\
\hline & & Family Halanaerobiaceae & TAS $[1,31]$ \\
\hline & & Genus Halanaerobium & TAS $[1-3,30]$ \\
\hline & & Species Halanaerobium praevalens & TAS $[1,2]$ \\
\hline & & Type strain GSL & TAS [2] \\
\hline & Gram stain & negative & TAS [2] \\
\hline & Cell shape & straight rods & TAS [2] \\
\hline & Motility & non-motile & TAS [2] \\
\hline & Sporulation & none & TAS [2] \\
\hline & Temperature range & above $5^{\circ} \mathrm{C}$ and below $60^{\circ} \mathrm{C}$ & TAS [2] \\
\hline & Optimum temperature & $37^{\circ} \mathrm{C}$ & TAS [2] \\
\hline & Salinity & $2 \%-30 \% \mathrm{NaCl}$, optimum at $13 \%$ & TAS [2] \\
\hline \multirow[t]{3}{*}{ MIGS-22 } & Oxygen requirement & strictly anaerobic & TAS [2] \\
\hline & Carbon source & yeast extract, trypticase & TAS [2] \\
\hline & Energy metabolism & chemoorganotroph & TAS [2] \\
\hline MIGS-6 & Habitat & saline environments & TAS [2] \\
\hline MIGS-15 & Biotic relationship & not reported & NAS \\
\hline \multirow[t]{3}{*}{ MIGS-14 } & Pathogenicity & not reported & NAS \\
\hline & Biosafety level & 1 & TAS [32] \\
\hline & Isolation & surface sediments of a saline lake & TAS [2] \\
\hline MIGS-4 & Geographic location & Great Salt Lake, Utah, USA & TAS [2] \\
\hline MIGS-5 & Sample collection time & between August 1979 and August 1980 & TAS [2] \\
\hline MIGS-4.1 & Latitude & 41.15 & NAS \\
\hline MIGS-4.2 & Longitude & -112.67 & NAS \\
\hline MIGS-4.3 & Depth & $10 \mathrm{~m}$ bottom sediment & TAS [2] \\
\hline MIGS-4.4 & Altitude & $1.755 \mathrm{~m}$ above sea level & NAS \\
\hline
\end{tabular}

Evidence codes - IDA: Inferred from Direct Assay (first time in publication); TAS: Traceable Author Statement (i.e., a direct report exists in the literature); NAS: Non-traceable Author Statement (i.e., not directly observed for the living, isolated sample, but based on a generally accepted property for the species, or anecdotal evidence). These evidence codes are from of the Gene Ontology project [33]. If the evidence code is IDA, the property was directly observed by one of the authors or an expert mentioned in the acknowledgements.

\section{Chemotaxonomy}

When grown on CS medium, at $5 \% \mathrm{NaCl}$, more lipids are produced than at $25 \% \mathrm{NaCl}(3.74 \%$ and $2.54 \%$ of the dry weight of the organism, respectively) [2]. At $5 \% \mathrm{NaCl}$, the fractions of glycolipids and phospholipids are $46.9 \%$ and $44.5 \%$ of the total lipids, respectively. At 25\%, the proportion changes in favor of phospholipids (49.1\%), whereas glycolipids decrease $(43.0 \%)$ [2]. The glycolipids consist of a single component diacylglycerol derivative, while the phospholipids consist mainly of cardiolipin (CL), phosphatidyl glycerol (PG), and three minor unidentified constituents [2]. When grown on CS medium, at 5\%, the major fatty acids are $\mathrm{C}_{14: 0}$ (49.3\%), $\mathrm{C}_{16: 1}$ (31.3\%) and $\mathrm{C}_{16: 0}$ $(11.4 \%)$. At $25 \%$, these fractions change to $36.8 \%$, $39 \%$, and $22.7 \%$, respectively. Similar though more detailed results on the fatty acid composition have been reported recently [6]. 


\section{Genome sequencing and annotation Genome project history}

This organism was selected for sequencing on the basis of its phylogenetic position [39], and is part of the Genomic Encyclopedia of Bacteria and Archaea project [40]. The genome project is depo- sited in the Genome On Line Database [19] and the complete genome sequence is deposited in GenBank. Sequencing, finishing and annotation were performed by the DOE Joint Genome Institute (JGI). A summary of the project information is shown in Table 2.

Table 2. Genome sequencing project information

\begin{tabular}{lll}
\hline MIGS ID & Property & Term \\
\hline MIGS-31 & Finishing quality & Finished \\
MIGS-28 & Libraries used & Three genomic libraries: one 454 pyrosequence standard library, \\
MIGS-29 & Sequencing platforms & Illumina GAii, 454 GS FLX Titanium \\
MIGS-31.2 & Sequencing coverage & $201.2 \times$ Illumina; $174.2 \times$ pyrosequence \\
MIGS-30 & Assemblers & Newbler version 2.3, Velvet, phrap \\
MIGS-32 & Gene calling method & Prodigal 1.4, GenePRIMP \\
& INSDC ID & CP002175 \\
& Genbank Date of Release & October 21, 2010 \\
& GOLD ID & Gc01415 \\
& NCBI project ID & 32591 \\
& Database: IMG-GEBA & 2503283011 \\
MIGS-13 & Source material identifier & DSM 2228 \\
& Project relevance & Tree of Life, GEBA \\
\hline
\end{tabular}

\section{Growth conditions and DNA isolation}

H. praevalens GSLT, DSM 2228, was grown anaerobically in DSMZ medium 210 ('Haloanaerobium' medium) [41] at $30-37^{\circ} \mathrm{C}$. DNA was isolated from 0.5-1 g of cell paste using MasterPure Grampositive DNA purification kit (Epicentre MGP04100) following the standard protocol as recommended by the manufacturer, with modification st/DL for cell lysis as described in Wu et al. [40]. DNA is available through the DNA Bank Network [42].

\section{Genome sequencing and assembly}

The genome was sequenced using a combination of Illumina and 454 sequencing platforms. All general aspects of library construction and sequencing can be found at the JGI website [43]. Pyrosequencing reads were assembled using the Newbler assembler (Roche). The initial Newbler assembly, consisting of 85 contigs in 31 scaffolds, was converted into a phrap [44] assembly by making fake reads from the consensus, to collect the read pairs in the 454 paired end library. Illumina sequencing data $(360 \mathrm{Mb})$ was assembled with Velvet [45] and the consensus sequences were shredded into $1.5 \mathrm{~kb}$ overlapped fake reads and assembled together with the 454 data. The 454 draft assembly was based on $401.6 \mathrm{Mb} 454 \mathrm{draft}$ data and all of the 454 paired end data. Newbler parameters are -consed -a 50 -l 350 -g -m -ml 20. The Phred/Phrap/Consed software package [44] was used for sequence assembly and quality assessment in the subsequent finishing process. After the shotgun stage, reads were assembled with parallel phrap (High Performance Software, LLC). Possible mis-assemblies were corrected with gapResolution [43], Dupfinisher [46], or sequencing cloned bridging PCR fragments with subcloning. Gaps between contigs were closed by editing in Consed, by PCR and by Bubble PCR primer walks (J.-F. Chang, unpublished). A total of 417 additional reactions and ten shatter libraries were necessary to close gaps and to raise the quality of the finished sequence. Illumina reads were also used to correct potential base errors and increase consensus quality using a software Polisher developed at JGI [47]. The error rate of the completed genome sequence is less than 1 in 100,000. Together, the combination of the Illumina and 454 sequencing platforms provided $375.4 \times$ coverage of the genome. The final assembly contained 838,597 pyrosequence and 12,903,210 Illumina reads. 


\section{Genome annotation}

Genes were identified using Prodigal [48] as part of the Oak Ridge National Laboratory genome annotation pipeline, followed by a round of manual curation using the JGI GenePRIMP pipeline [49]. The predicted CDSs were translated and used to search the National Center for Biotechnology Information (NCBI) non-redundant database, UniProt, TIGR-Fam, Pfam, PRIAM, KEGG, COG, and InterPro databases. Additional gene prediction analysis and functional annotation was performed within the Integrated Microbial Genomes - Expert Review (IMG-ER) platform [50].

\section{Genome properties}

The genome consists of a 2,309,262 bp long chromosome with a $\mathrm{G}+\mathrm{C}$ content of $30.3 \%$ (Figure 3 and Table 3). Of the 2,180 genes predicted, 2,110 were protein-coding genes, and 70 RNAs; 42 pseudogenes were also identified. The majority of the protein-coding genes $(77.7 \%)$ were assigned with a putative function while the remaining ones were annotated as hypothetical proteins. The distribution of genes into COGs functional categories is presented in Table 4.

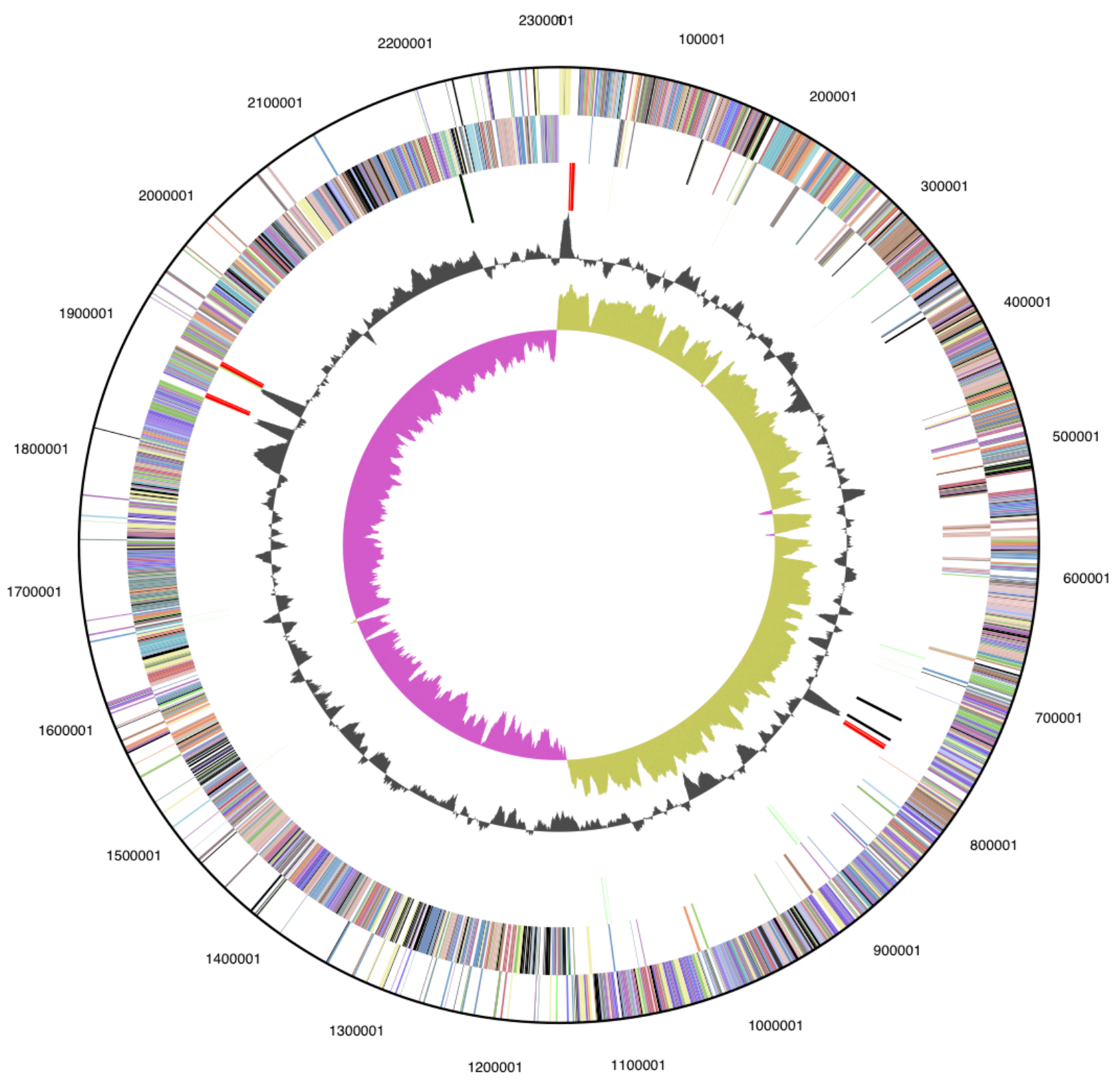

Figure 3. Graphical circular map of the chromosome. From outside to the center: Genes on forward strand (color by COG categories), Genes on reverse strand (color by COG categories), RNA genes (tRNAs green, rRNAs red, other RNAs black), GC content, GC skew. 
Table 3. Genome Statistics

\begin{tabular}{lrr}
\hline Attribute & Value & \% of Total \\
\hline Genome size (bp) & $2,309,262$ & $100.00 \%$ \\
DNA coding region (bp) & $2,059,925$ & $89.20 \%$ \\
DNA G+C content (bp) & 699,559 & $30.29 \%$ \\
Number of replicons & 1 & \\
Extrachromosomal elements & 0 & \\
Total genes & 2,180 & $100.00 \%$ \\
RNA genes & 70 & $3.21 \%$ \\
rRNA operons & 4 & \\
Protein-coding genes & 2,110 & $96.79 \%$ \\
Pseudo genes & 42 & $1.93 \%$ \\
Genes with function prediction & 1,694 & $77.71 \%$ \\
Genes in paralog clusters & 310 & $14.22 \%$ \\
Genes assigned to COGs & 1,760 & $80.73 \%$ \\
Genes assigned Pfam domains & 1,860 & $85.32 \%$ \\
Genes with signal peptides & 446 & $20.46 \%$ \\
Genes with transmembrane helices & 582 & $26.70 \%$ \\
CRISPR repeats & 1 & \\
\hline
\end{tabular}

Table 4. Number of genes associated with the general COG functional categories

\begin{tabular}{lrrl}
\hline Code & value & \%age & Description \\
\hline J & 133 & 6.9 & Translation, ribosomal structure and biogenesis \\
A & 0 & 0.0 & RNA processing and modification \\
K & 124 & 6.4 & Transcription \\
L & 115 & 6.0 & Replication, recombination and repair \\
B & 1 & 0.0 & Chromatin structure and dynamics \\
D & 24 & 1.2 & Cell cycle control, cell division, chromosome partitioning \\
Y & 0 & 0.0 & Nuclear structure \\
V & 18 & 0.9 & Defense mechanisms \\
T & 126 & 6.5 & Signal transduction mechanisms \\
M & 106 & 5.5 & Cell wall/membrane/envelope biogenesis \\
N & 76 & 3.9 & Cell motility \\
Z & 0 & 0.0 & Cytoskeleton \\
W & 0 & 0.0 & Extracellular structures \\
U & 44 & 2.3 & Intracellular trafficking, secretion, and vesicular transport \\
O & 66 & 3.4 & Posttranslational modification, protein turnover, chaperones \\
C & 123 & 6.4 & Energy production and conversion \\
G & 150 & 7.8 & Carbohydrate transport and metabolism \\
E & 136 & 7.0 & Amino acid transport and metabolism \\
F & 74 & 3.8 & Nucleotide transport and metabolism \\
H & 80 & 4.1 & Coenzyme transport and metabolism \\
I & 45 & 2.3 & Lipid transport and metabolism \\
P & 121 & 6.3 & Inorganic ion transport and metabolism \\
Q & 18 & 0.9 & Secondary metabolites biosynthesis, transport and catabolism \\
R & 186 & 9.6 & General function prediction only \\
S & 168 & 8.7 & Function unknown \\
- & 420 & 19.3 & Not in COGs \\
\hline
\end{tabular}




\section{Acknowledgements}

We would like to gratefully acknowledge the help of Olivier D. Ngatchou-Djao (HZI) for drafting the manuscript, and Helga Pomrenke (DSMZ) for growing $H$. praevalens cultures. This work was performed under the auspices of the US Department of Energy Office of Science, Biological and Environmental Research Program, and by the University of California, Lawrence Berkeley National Laboratory under contract No. DE-

\section{References}

1. Validation of the publication of new names and new combinations previously effectively published outside the IJSB. List No. 16. Int J Syst Bacteriol 1984; 34:503-504. doi:10.1099/00207713$\underline{34-4-503}$

2. Zeikus JG, Hegge PW, Thompson TE, Phelps TJ, Langworthy TA. Isolation and description of Haloanaerobium praevalens gen. nov. and sp. nov., an obligately anaerobic halophile common to Great Salt Lake sediments. Curr Microbiol 1983; 9:225-233. doi:10.1007/BF01567586

3. Oren A. Change of the names Haloanaerobiales, Haloanaerobiaceae and Haloanaerobium to Halanaerobiales, Halanaerobiaceae and Halanaerobium, respectively, and further nomenclatural changes within the order Halanaerobiales. Int J Syst Evol Microbiol 2000; 50:2229-2230. PubMed doi:10.1099/00207713-50-6-2229

4. Euzéby JP. List of bacterial names with standing in nomenclature: a folder available on the Internet. Int J Syst Bacteriol 1997; 47:590-592. PubMed doi:10.1099/00207713-47-2-590

5. Kobayashi T, Kimura B, Fujii T. Strictly anaerobic halophiles isolated from canned Swedish fermented herrings (Surströmming). Int J Food Microbiol 2000; 54:81-89. PubMed doi:10.1016/S0168-1605(99)00172-5

6. Eder W, Jahnke LL, Schmidt M, Huber R. Microbial diversity of the brine-seawater interface of the Kebrit Deep, Red Sea, studied via 165 rRNA gene sequences and cultivation methods. Appl Environ Microbiol 2001; 67:3077-3085. PubMed doi:10.1128/AEM.67.7.3077-3085.2001

7. Tsai CR, Garcia JL, Patel BKC, Cayol JL, Baresi L, Mah RA. Haloanaerobium alcaliphilum sp. nov., an anaerobic moderate halophile from the sediments of Great Salt Lake, Utah. Int I Syst Bacteriol 1995; 45:301-307. PubMed doi:10.1099/00207713-45-2-301

8. Ravot G, Casalot L, Ollivier B, Loison G, Magot M. rdlA, a new gene encoding a rhodanese-like
AC02-05CH11231, Lawrence Livermore National Laboratory under Contract No. DE-AC52-07NA27344, and Los Alamos National Laboratory under contract No. DEAC02-06NA25396, UT-Battelle and Oak Ridge National Laboratory under contract DE-AC05-000R22725, as well as German Research Foundation (DFG) INST 599/1-2.

protein in Halanaerobium congolense and other thiosulfate-reducing anaerobes. Res Microbiol

2005; 156:1031-1038. PubMed doi:10.1016/j.resmic.2005.05.009

9. Cayol JL, Ollivier B, Patel BKC, Ageron E, Grimont PAD, Prensier G, Garcia JL. Haloanaerobium lacusroseus sp. nov., an extremely halophilic fermentative bacterium from the sediments of a hypersaline Lake. Int I Syst Bacteriol 1995;

45:790-797. PubMed doi:10.1099/00207713-454-790

10. Bhupathiraju VK, Mclnerney MJ, Woese CR, Tanner RS. Haloanaerobium kushneri sp. nov., an obligately halophilic, anaerobic bacterium from an oil brine. Int J Syst Bacteriol 1999; 49:953-960. PubMed doi:10.1099/00207713-49-3-953

11. Oren A, Gofshtein-Gandman LV, Keynan A. Hydrolysis of N'-benzoyl-D-arginine-p-nitroanilide by members of the Haloanaerobiaceae: additional evidence that Haloanaerobium praevalens is related to endospore-forming bacteria. FEMS Microbiol Lett 1989; 58:5-10.

12. Oren A, Gurevich P. The fatty acid synthetase complex of Haloanaerobium praevalens is not inhibited by salt. FEMS Microbiol Lett 1993;

108:287-290. doi:10.1111/j.15746968.1993.tb06117.x

13. DeSantis TZ, Hugenholtz $P$, Larsen N, Rojas $M$, Brodie E, Keller K, Huber T, Dalevi D, Hu P, Andersen G. Greengenes, a chimera-checked $16 \mathrm{~S}$ rRNA gene database and workbench compatible with ARB. Appl Environ Microbiol 2006;

72:5069-5072. PubMed doi:10.1128/AEM.03006-05

14. Porter MF. An algorithm for suffix stripping. Program: electronic library and information systems. 1980; 14:130-137.

15. Castresana J. Selection of conserved blocks from multiple alignments for their use in phylogenetic analysis. Mol Biol Evol 2000; 17:540-552. PubMed 
16. Lee C, Grasso C, Sharlow MF. Multiple sequence alignment using partial order graphs. BioinformatiCs 2002; 18:452-464. PubMed doi:10.1093/bioinformatics/18.3.452

17. Stamatakis A, Hoover $\mathrm{P}$, Rougemont J. A rapid bootstrap algorithm for the RAxML Web servers. Syst Biol 2008; 57:758-771. PubMed doi:10.1080/10635150802429642

18. Pattengale ND, Alipour M, Bininda-Emonds ORP, Moret BME, Stamatakis A. How many bootstrap replicates are necessary? Lect Notes Comput Sci 2009; 5541:184-200. doi:10.1007/978-3-64202008-7_13

19. Liolios K, Chen IM, Mavromatis K, Tavernarakis N, Hugenholtz P, Markowitz VM, Kyrpides NC. The Genomes On Line Database (GOLD) in 2009: status of genomic and metagenomic projects and their associated metadata. Nucleic Acids Res 2010; 38:D346-D354. PubMed doi:10.1093/nar/gkp848

20. Mavromatis K, Ivanova N, Anderson I, Lykidis A, Hooper SD, Sun H, Kunin V, Lapidus A, Hugenholtz P, Patel B, Kyrpides NC. Genome analysis of the anaerobic thermohalophilic bacterium Halothermothrix orenii. PLOS ONE 2009; 4:e4192. PubMed doi:10.1371/journal.pone.0004192

21. Field D, Garrity G, Gray T, Morrison N, Selengut J, Sterk P, Tatusova T, Thomson N, Allen MJ, Angiuoli $\mathrm{SV}$, et al. The minimum information about a genome sequence (MIGS) specification. Nat Biotechnol 2008; 26:541-547. PubMed doi:10.1038/nbt1360

22. Garrity G. NamesforLife. BrowserTool takes expertise out of the database and puts it right in the browser. Microbiol Today 2010; 37:9.

23. Woese CR, Kandler O, Wheelis ML. Towards a natural system of organisms: proposal for the domains Archaea, Bacteria, and Eucarya. Proc Natl Acad Sci USA 1990; 87:4576-4579. PubMed doi:10.1073/pnas.87.12.4576

24. Garrity GM, Holt JG. The Road Map to the Manual. In: Garrity GM, Boone DR, Castenholz RW (eds), Bergey's Manual of Systematic Bacteriology, Second Edition, Volume 1. Springer, New York 2001:119-169.

25. Gibbons NE, Murray RGE. Proposals concerning the higher taxa of Bacteria. Int / Syst Bacteriol 1978; 28:1-6. doi:10.1099/00207713-28-1-1

26. Validation list 132. List of new names and new combinations previously effectively, but not valid- ly, published. Int J Syst Evol Microbiol 2010;

60:469-472. doi:10.1099/ijs.0.022855-0

27. Rainey FA. Class II. Clostridia class nov. In: De Vos P, Garrity G, Jones D, Krieg NR, Ludwig W, Rainey FA, Schleifer KH, Whitman WB (eds), Bergey's Manual of Systematic Bacteriology, Second Edition, Volume 3, Springer-Verlag, New York, 2009, p. 736.

28. Validation List No. 55. Validation of the publication of new names and new combinations previously effectively published outside the IJSB. Int J Syst Bacteriol 1995; 45:879-880. doi:10.1099/00207713-45-4-879

29. Judicial Commission of the International Committee on Systematics of Prokaryotes. The nomenclatural types of the orders Acholeplasmatales, Halanaerobiales, Halobacteriales, Methanobacteriales, Methanococcales, Methanomicrobiales, Planctomycetales, Prochlorales, Sulfolobales, Thermococcales, Thermoproteales and Verrucomicrobiales are the genera Acholeplasma, Halanaerobium, Halobacterium, Methanobacterium, Methanococcus, Methanomicrobium, Planctomyces, Prochloron, Sulfolobus, Thermococcus, Thermoproteus and Verrucomicrobium, respectively. Opinion 79. Int J Syst Evol Microbiol 2005; 55:517-518. PubMed doi:10.1099/ijs.0.63548-0

30. Rainey FA, Zhilina TN, Boulygina ES, Stackebrandt E, Tourova TP, Zavarzin GA. The taxonomic status of the fermentative halophilic anaerobic bacteria: description of Haloanaerobiales ord. nov., Halobacteroidaceae fam. nov., Orenia gen. nov. and further taxonomic rearrangements at the genus and species level. Anaerobe 1995; 1:185-199. PubMed doi:10.1006/anae.1995.1018

31. Oren A, Paster BJ, Woese CR. Haloanaerobiaceae: a new family of moderately halophilic, obligately anaerobic bacteria. Syst Appl Microbiol 1984; 5:71-80.

32. BAuA. Classification of bacteria and archaea in risk groups. TRBA 2005; 466:84.

33. Ashburner M, Ball CA, Blake JA, Botstein D, Butler $\mathrm{H}$, Cherry JM, Davis AP, Dolinski K, Dwight SS, Eppig JT, et al. Gene Ontology: tool for the unification of biology. Nat Genet 2000; 25:25-29. $\underline{\text { PubMed doi:10.1038/75556 }}$

34. Oren A, Gurevich P, Henis Y. Reduction of nitrosubstituted aromatic compounds by the halophilic anaerobic eubacteria Haloanaerobium praevalens and Sporohalobacter marismortui. Appl Environ Microbiol 1991; 57:3367-3370. PubMed 
35. Oren A, Weisburg WG, Kessel M, Woese CR. Halobacteroides halobius gen. nov., sp. nov., a moderately halophilic anaerobic bacterium from the bottom sediments of the dead sea. Syst Appl Microbiol 1984; 5:58-70.

36. Oren A. The ecology and taxonomy of anaerobic halophilic eubacteria. FEMS Microbiol Rev 1986; 39:23-29. doi:10.1111/j.15746968.1986.tb01838.x

37. Oren A. 2006. Life at high salt concentrations. In: M Dworkin, S Falkow, E Rosenberg, KH Schleifer E Stackebrandt (eds), The Prokaryotes, 3. ed, vol. 2. Springer, New York, p. 263-282.

38. Matheson AT, Louie KA, Tak BD, Zuker M. The primary structure of the ribosomal A-protein (L12) from the halophilic eubacterium Haloanaerobium praevalens. Biochimie 1987; 69:1013-1020. PubMed doi:10.1016/0300-9084(87)90001-0

39. Klenk HP, Göker M. En route to a genome-based classification of Archaea and Bacteria? Syst Appl Microbiol 2010; 33:175-182. PubMed doi:10.1016/j.syapm.2010.03.003

40. Wu D, Hugenholtz P, Mavromatis K, Pukall R, Dalin E, Ivanova NN, Kunin V, Goodwin L, Wu $M$, Tindall BJ, et al. A phylogeny-driven genomic encyclopaedia of Bacteria and Archaea. Nature 2009; 462:1056-1060. PubMed doi:10.1038/nature08656

41. List of growth media used at DSMZ: http://www.dsmz.de/microorganisms/media list.p hp.

42. Gemeinholzer B, Dröge G, Zetzsche H, Haszprunar G, Klenk HP, Güntsch A, Berendsohn WG, Wägele JW. The DNA Bank Network: the start from a German initiative. Biopreservation and Biobanking 2011; 9:51-55.

doi:10.1089/bio.2010.0029

43. JGl website. http://www.jgi.doe.gov

44. The Phred/Phrap/Consed software package. http://www.phrap.com

45. Zerbino DR, Birney E. Velvet: algorithms for de novo short read assembly using de Bruijn graphs. Genome Res 2008; 18:821-829. PubMed doi:10.1101/gr.074492.107

46. Han C, Chain P. Finishing repeat regions automatically with Dupfinisher. In: Proceeding of the 2006 international conference on bioinformatics \& computational biology. Arabnia HR, Valafar $\mathrm{H}$ (eds), CSREA Press. June 26-29, 2006: 141-146.

47. Lapidus A, LaButti K, Foster B, Lowry S, Trong S, Goltsman E. POLISHER: An effective tool for using ultra short reads in microbial genome assembly and finishing. AGBT, Marco Island, FL, 2008

48. Hyatt D, Chen GL, LoCascio PF, Land ML, Larimer FW, Hauser LJ. Prodigal: prokaryotic gene recognition and translation initiation site identification. BMC Bioinformatics 2010; 11:119. PubMed doi:10.1186/1471-2105-11-119

49. Pati A, Ivanova NN, Mikhailova N, Ovchinnikova G, Hooper SD, Lykidis A, Kyrpides NC. GenePRIMP: a gene prediction improvement pipeline for prokaryotic genomes. Nat Methods 2010; 7:455-457. PubMed doi:10.1038/nmeth.1457

50. Markowitz VM, Ivanova NN, Chen IMA, Chu K, Kyrpides NC. IMG ER: a system for microbial genome annotation expert review and curation. Bioinformatics 2009; 25:2271-2278. PubMed doi:10.1093/bioinformatics/btp393 